Libraries and Culture. Vol. 39, No. 3, (2004) p. 245-259

ISSN: $1534-7591$ (online) 0894-8631 (print)

DOI: $10.1353 /$ lac.2004.0058

(C) 2004 University of Texas Press

http://www.utexas.edu/utpress/journals/journals.html

http://muse.jhu.edu/journals/lac/

\title{
Classification and the Definition of a Discipline: The Dewey Decimal Classification and Home Economics
}

\section{Anne M. Fields and Tschera Harkness Connell}

Few not directly involved with the history of home economics may be aware of Melvil Dewey's close involvement with that discipline's early development. Early leaders in home economics attempted to have the subject subdivided between its original placement in the Dewey Decimal Classification (DDC) in the 600s (Useful Arts) and a complementary placement as a subdivision of the 300 s (Sociology). The failure of this attempt illuminates Dewey's well-known resistance to tinkering with the DDC, internecine struggles within the discipline, and the discipline's gender-driven place within American culture.

Few librarians are aware that the roots of home economics as a discipline lie in the Lake Placid Conferences on Home Economics, hosted annually from 1899 through 1908 by Melvil Dewey and his wife, Annie Godfrey Dewey. With the exception of 1903, when the conference was held in Boston in conjunction with the National Education Association, and 1908, when the conference was held at the Chautauqua Institute, these meetings were held at the Lake Placid Club, the upstate New York retreat developed in 1893 by the Deweys. Encouraged by the Deweys, conference participants sought to nurture education in home economics at all academic levels and to define a discipline still called "a preeminent example of a gendered domain."

The struggle to define the discipline is reflected in the definition presented at the fourth Lake Placid conference in 1902, a definition that to some degree still stands today:

1. Home economics in its most comprehensive sense is the study of laws, conditions, principles and ideals which are concerned on the one hand with man's immediate physical environment and on the other hand with his nature as a social being, and is the study specifically of the relation between those two factors.

2. In a narrow sense the term is given to the study of the empirical sciences with special reference to the practical problems of housework, cooking etc. ${ }^{2}$

Conferees believed that the dual aspects of this definition-narrow "immediate" and broad "social"-characterized the nascent discipline in such a way as would win it a place at the academic table among more prestigious disciplines such as sociology and economics.

As conferees sought to clarify the social aspect of that disciplinary identity, one strategy they adopted was an ultimately unsuccessful attempt to subdivide home economics within the seventh edition of the Dewey Decimal Classification (DDC). This proposal would have subdivided the subject by relocating its economic and sociologic aspects to the 300s (Sociology) under 339, in place of Pauperism. (Pauperism would have been given the classification 339.9 because it was viewed as the result of the absence of Domestic Economy.) The subject's technical applications would have remained in the 600s (Useful Arts) under 640 Domestic Economy. The 
home economists believed that relocating the more social aspects of the subject would have moved the discipline into a more prestigious location within Dewey's scheme, probably the most widely accepted representation of knowledge at the time or since. Their failure to achieve this goal not only illuminates Dewey's well-known resistance to tinkering with the DDC but also illuminates both internecine struggles within early home economics and the subject's gender-determined place within early-twentieth-century culture.

The sixth edition of the DDC was published in 1899, the seventh in 1911. These dates roughly bookended the Lake Placid conferences, which after 1908 and the founding of the American Home Economics Association moved on to other venues because attendance had grown so large. The Lake Placid Club as place represented the Deweys' commitment "to establishing and fostering a model community developed for the recreation and rest of professional people that would become an example to the nation of how households should be run efficiently, inexpensively, and in accordance with the best principles of the domestic sciences advocated by home economists. ${ }^{13}$ Thus it seemed an especially appropriate place to begin formalizing home economics as a discipline.

Annie Dewey actively participated in all the conferences, serving as, among other things, recording secretary and chair of the Classification and Bibliography, Standards of Living, and Standard Living Wage Committees. Melvil Dewey attended all but the fifth and seventh conferences, his absence from the seventh being attributed to his attendance at the Pacific Coast American Library Association meeting. On behalf of the Lake Placid Club trustees he officially welcomed conference participants to all the conferences he attended, except the tenth, which was held at the Chautauqua Institute. Conference proceedings show that he gave additional presentations or participated in the discussions of the first, third, eighth, ninth, and tenth conferences and was appointed chair of the Finance Committee for the ninth conference.

Good feeling and excitement filled the early meetings, but giving birth to the discipline was not uncomplicated. For example, the discipline's name was a perennial source of debate. While the eleven participants in the first conference in 1899 agreed to name the discipline "home economics," regular reports by the Committee on Nomenclature reveal continuing concern. The proceedings of the sixth conference record that Lake Placid conference founder and president Ellen H. Swallow Richards had suggested "ecology" as a name, but when she discovered that botanists already were using this term she moved on to the term "euthenics," or "better living," a turn on the word "eugenics," which had been coined by Sir Francis Galton in the late nineteenth century to denote the science of developing a "better race." Instead of "euthenics" as a global name, however, conferees complicated the issue by choosing the names "handwork" (for elementary school), "domestic science" (for secondary school), "home economics" (for normal and professional school), and "euthenics" (for higher education) to represent the field at various levels of schooling, perhaps in an attempt to satisfy everyone. ${ }^{4}$ Beginning in 1912 , several years after the founding of the American Home Economics Association, the names yet again were consolidated into "home economics."

The choice of name and the effort to relocate the more social aspects of the discipline to 339 were related to each other. Wayne Wiegand indicates that at least part of the rationale for the early proposal to divide home economics within the DDC was that sociology and economics had more prestige as disciplines than did home economics. ${ }^{5}$ The proceedings of the first Lake Placid conference indeed reported that home economics was to be chosen as the name for the discipline so that it could find a logical place in college and university curricula and not be confused with "mere household arts." ${ }^{16}$ Keeping the subject of home economics in one subdivision, the 640s, 
artificially emphasized narrow "events and phenomena" such as cooking and sewing over broader, more "relational" aspects of the subject. Unfortunately, the multiple shifting names may have conveyed a schizophrenic image that ill served the home economists' efforts to legitimize themselves within the DDC.

Nevertheless, at least two of Melvil Dewey's speeches to the conferees seemed to support the home economists' claim to a relationship between the home and the rest of society. At the eighth conference he delivered an address on "The Trend Toward the Practical in Education" in which he declared the relationship between home and society, proclaiming, "The scientific study of food and clothes and shelter, of personal and home hygiene, of home training, reading and other forms of education and recreations, in short of all those things that pertain to the home, is the greatest problem with which the race now has to deal. It is a corner stone on which the best in civilization will be built." At the tenth conference he highlighted the concept of "relation," the home economists' key definitional term, tying it to the concept of sociology in an address on "The Future of Home Economics": "The application of science to the home is as important as any other study. The relation of man to man is equally important. The $18^{\text {th }}$ century was essentially the theologic, the $19^{\text {th }}$ century was scientific, and the $20^{\text {th }}$ century is sociologic. ${ }^{8}$ Later, in a memorial to Ellen Richards written with Annie Dewey in 1911, the concept of relation was invoked. Recalling the impetus for the first conference, the Deweys wrote, "With changing industrial and economic conditions, the home, the unit of society, was failing to meet the needs of better citizenship. Disintegration of the family was seen on every side. There was frightful waste of human efficiency because of ignorance of right living and overwork under wrong conditions." Home economics curricula, they insisted, were necessary to instill "knowledge of the true relation of things to the welfare of the individual and giv[e] to the people a sense of control over their environment." 9

Establishing an appropriate classification scheme for the subject of home economics as a body of knowledge was considered a key task by the conferees. In the proceedings of the second conference Henrietta Goodrich, director of the Boston School of Housekeeping, insisted that along with establishing both undergraduate and graduate school curricula and a "laboratory for research in home and social economics," one more thing was essential: "To increase the body of exact knowledge, to formulate and classify the unwieldy material that we have already collected, these are the tasks that must be accomplished before we can claim a true science of home economics, or dignify its applications as 'professions."'10

Home economics was not alone in its disciplinary birth pangs at the turn of the twentieth century. With the coming of interest in American social reform had come the founding of the American Social Science Association in 1865. Melvil Dewey had founded the American Library Association in 1876. The turn of the century witnessed the organization of the major social sciences-economics, psychology, anthropology, political science, and sociology-into their professional organizations, helping to give the imprimatur to them as academic disciplines."

Along with home economics, professions such as medicine, law, education, nursing, and social work also organized themselves during the same period. Part of the growth process of these disciplines was to found professional organizations, to publish journals, to hold meetings, and to establish curricula within institutions of higher learning. The home economists, who began publishing the precursor to the Journal of Home Economics in 1908 and founded the American Home Economics Association in 1909, used the Lake Placid conferences as their first organizational annual meetings. The development of the higher education curriculum was a prominent topic at all ten meetings. What distinguished home economics from other social 
sciences, however, was its leaders' attempt to conceptualize their discipline in terms of the DDC.

In the sixth edition of the DDC, the classification of domestic economy under 640 placed it at the same level as other applied technologies such as Medicine, Engineering, Agriculture, and Communications and Commerce. The proceedings of the first conference recorded that Dewey "explained the decimal method used in the state library and it was agreed that in future classification home economics should be brought out as a distinct section of sociology with the number 339." "Public libraries should present as complete collections as possible of books relating to the whole subject, showing not only the best modern thought but all that bears on history and development of household arts and home economics," the proceedings continued. These statements of agreement were not attributed to anyone in particular, but the proceedings do note that "the conference decided" to help the New York State Library continue to build the collection it had already started. ${ }^{12}$ Thus, the amplified classification scheme was intended to accompany the development of a centralized home economics collection and bibliography that would represent the accumulated knowledge of the subject as completely as possible.

At the second conference a committee led by Annie Dewey presented "a tentative classification" of home economics that, the proceedings recorded, "recognizes its place in sociology under economics of consumption" by partially relocating home economics to 339 and renaming that classification "economics of consumption. ${ }^{13}$ Pauperism would be incorporated as one of its subdivisions as 339.9 because, according to the home economists' logic, the right practice of home economy would bring about the end of poverty. Certain topics such as cooking, food, and furnishings would remain in the $640 \mathrm{~s}$. Frequent cross-references between the $339 \mathrm{~s}$ and the 640 s would clarify the relationship between the broader and narrower aspects of home economics.

The DDC usually provides a single home for a particular subject, complemented where necessary by cross-references, rather than the dual placement the home economists proposed. The sixth edition did provide precedent for their proposal, however. Commerce and Communication were divided between 380 and 650, the note for 380 instructing, "The technical side of these questions goes mostly in 650, Useful Arts. Here [in 380] belong discussions of social and political relations; e.g., government control of railroads, telegraphs, etc." 14

Because Dewey had introduced the classification to the conferees in the first place, the conference proceedings at least imply that he seemed to have received their suggestion favorably. Furthermore, the 1911 Ellen Richards memorial issue of the Journal of Home Economics reprints a "Greeting" apparently presented to Richards by the seventh conference attendees in 1905 but not cited in the proceedings themselves that hails her leadership in this regard: "By able committees whose work has extended over several years, [the Lake Placid conference] has obtained through the catalogue system of the American Library Association the proper place for books on House [sic] Economics, thus smoothing the path of students in this and kindred lines." ${ }^{15}$ The conference proceedings, however, made no further mention of any change to the DDC, even when Annie Dewey gave the report of the Standing Committee on Classification, Bibliography, and Syllabuses at the fifth conference in 1903. In fact, the committee dropped the word "Classification" from its name after 1904. It is possible that the committee dropped the word because they had given up on the DDC project; it also is possible that they assumed that home economics was going to be split between 339 and 640 and that "classification" no longer would be relevant to the committee's purpose.

What is clearer, however, is that the Lake Placid conference bibliographic project was low on the participants' list of priorities. In 1901 a fifteen-hundred-item bibliography of works on 
home economics published in English between 1850 and 1899 and held by the New York State Library was distributed to the participants and later published as Bibliography of Domestic Economy in English: New York State Library Bulletin No. 52 under the authorship of Robert Kendall Shaw. ${ }^{16}$ The books in the bibliography were classified according to the scheme proposed by the conference participants, but only twelve were classified under 339.1 Home Economics. All twelve featured titles related to the general domestic cost of living such as How She Did It; or, Comfort on $\$ 150$ a Year by Mary Cruger and How to Live Well on Sixpence a Day by Thomas L. Nichols, with Ellen Henrietta (Swallow) Richards's Cost of Living as Modified by Sanitary Science included for good measure. Most titles remained in the 640s with topics such as Dora Groome's $U p$ to Date Economical Cookery, Frederick Edwards's Economical Use of Fuel and Prevention of Smoke, and Mrs. Eliza Warren's House and Its Furnishings: How to Choose a House and Furnish It at a Small Expense. Although the conferees probably hoped that additional titles would join the ones in the 339s, the disparity between the number of titles classified under 339 and 640 may not have impressed Melvil Dewey.

Collocating the recorded knowledge of home economics into centrally accessible collections initially was considered an important goal of the Lake Placid conferences, and participants were encouraged to review and submit books to be added to the collection at the New York State Library. In 1904, however, Annie Dewey resigned from the committee because "little or nothing ha[d] been done for several years owing to pressure of other work." ${ }^{17}$ Her successor as chair, Maria Eliott, had even less success. Urging participants at the eighth conference to recall that they had agreed at the previous conference to continue with the bibliography project yet had not submitted a single recommendation or review, she admonished them, "Please turn to p. 95, paragraph 6 of our last proceedings; read, repent and reform." ${ }^{18}$

Despite the apparent expectations of the Lake Placid participants, ultimately the "relational" aspects of home economics were not relocated to 339 in the seventh edition. ${ }^{19}$ The 640 s were vastly expanded in detail, however, from less than one page to eleven pages, lower only than chemistry, anatomy and physiology, and engineering in the number of additional entries. It is certainly possible that this attention to detail in the 640s reflected the Deweys' personal interest in home economics. It may even have reflected an attempt on Melvil Dewey's part to placate his wife and the home economists whose desire to have their discipline partially relocated to 339 he evidently had not championed.

Dewey s reasons for ultimately rejecting the Lake Placid proposal probably always will remain unclear, but some factors may be suggested.

A taxonomic history of the DDC reveals that, overall, Dewey advocated the "integrity of numbers" or "stability of numbers" view. ${ }^{20}$ That is, he was more concerned with the effect of changes in the classification system on existing library collections than he was with reflecting possibly ephemeral changes in the structure of subject disciplines. In the introduction to the second edition of the DDC, he had pledged a henceforth conservative approach to the system's users: "Librarians making the necessary changes for the revised edition need not fear that a series of editions hav begun each of which will call for such changes.... [W] hile the first edition was in its nature tentative, this one may be considered as having the numbers settled after sufficient trial and not likely to be again altered, tho of course certain subjects not yet subdivided will in due time have subdivisions added, and suggestions from specialists are invited."21

Instead of relocating subjects between or among classes, Dewey preferred subdividing classes, a philosophy exemplified by incorporating additional specific categories of food into the seventh edition of the DDC. In 1920 he wrote in his legendary simplified spelling in Library 
Journal, "Each year someone is troubled becauz we fail to make what he calls 'improvements,' but we chek up with great care all these sugjestions and if a large majority of those whose criticism we hav found reliable, agree that the proposed chanje would do more harm than good, we have politely to lay it on the table, often to the proposer's annoyance." ${ }^{12}$ Responding to an article byjuel Dieserud of Chicago's Field Columbian Museum, Dewey and assistant DDC editor W. S. Biscoe wrote, "We want a scheme of classification suited for general adoption. ... It must not be one classification for the scientist, another for the sociologist, a third for the theologian, etc." ${ }^{23}$ They could just as easily have added, "a fourth for the home economist." Nevertheless, if one jumps ahead to 1926 and looks at the works classified in the A.L.A. Catalog, the books then listed under 339 Poverty, Conservation, such as John Lewis Gillen's Poverty and Dependency: Their Relief and Prevention and Maurice Farr Parmelee's Poverty and Social Progress, might well have been friendly neighbors to books on the more domestic aspects of consumption then listed in the 640s, such as S. Agnes Donham's Spending the Family Income, Isabel Ely Lord's Getting Your Money's Worth, and Clarence Wilbur Taber and R. A. Wardall's Economics of the Family. ${ }^{2}{ }^{*}$

It may be that, along with Melvil Dewey's generally conservative practices regarding the DDC, his conservative view specifically with regard to home economics' placement within the classification system was warranted by tensions within the discipline itself about the placement of home economics within the curriculum, especially at the postsecondary level.

The passage of the Morrill Act of 1862 had provided public lands and funds to states for the purposes of agricultural and mechanical education, including home economics. ${ }^{25}$ The courses that grew out of this educational movement had both positive and negative effects on home economics as an academic discipline. On the positive side, they provided postsecondary educational and employment opportunities for women at a time when such opportunities were rare.

On the negative side, they provided ammunition to opponents who believed that separate but equal courses for women demeaned women. For example, in June 1905, the same year as the eighth conference, a committee of the Association of Collegiate Alumnae (ACA), the precursor to the American Association of University Women, proposed a resolution:

We believe that home economics belongs in a professional course which should fit pupils for practical life, and that such a course taken after leaving college in connection with practical housekeeping will be of much greater value. We believe that as an applied science it has not the same educational value as courses that give liberal training and that our future home makers should have the broadest liberal training upon which to base technical knowledge.

Therefore, Resolved that it is the opinion of those present at this meeting that home economics as such has no place in a college course for women. ${ }^{26}$

The authors of this resolution argued for women having the same strong grounding in Greek and Latin that was available to men, something for which M. Carey Thomas, president of Bryn Mawr, had argued in 1893 when she characterized home economics as "too sex stereotyped to fit in a curriculum designed to replicate the rigors of the male Ivy League colleges." ${ }^{27}$ Smith and Wellesley had begun to offer courses in home economics, but other schools worried about the association with Boston cooking schools and less prestigious midwestern colleges. Although no evidence shows that the few members attending the ACA committee meeting ever voted on the resolution, the feelings behind it were clearly dismissive of the place of home economics in the postsecondary curriculum. 
On the other hand, in the proceedings of the ninth conference, held the year following the ACA proposal, that conference's standing committee reported that "under other names than home economics" the number of courses in home economics was growing. The committee quoted a botany professor from an unspecified eastern women's college as having written, "'Any subject which combines the possibility of thoro scientific treatment with practical uses, is not only as cultural in its nature as any subject whatever, but it arouses so much more of real interest in the students as to make it more cultural, while the fact that it is useful is just much pure gain."' "What stronger plea could be given for introduction of home economics into college work?" asked the committee. ${ }^{28}$ This rhetorical question echoed the elaboration of the original definition of home economics proposed back in 1902: "If there is any fitness at all in the definition suggested, or if it even hints at the right way to consider home economics, i.e., as primarily a study of connections and relations between certain phases of man's nature, home economics might be introduced without offense in the most conservative even of eastern colleges, while more liberal institutions would have in their courses of study, as a subhead under home economics, courses which would make practical application of the empirical and technical sciences. ${ }^{29}$

Home economics as a discipline shared much the same kind of marginalized position within academia as did teacher education, even within its own schools and departments. Henry Johnson of Columbia University's Teachers College captured this reduced status in his memoir when he recalled the head of Columbia's Graduate Department of History greeting him in 1906 with "'Be you the guy that teaches them methods at Teachers College?"'130 Almost contemporaneously, Dewey recounted in 1908, "Several years ago when I suggested to a college president that he add home economics to his curriculum he was as much surprised as if I had askt him to add to his faculty the cook of the college dormitory."

The college president's surprise typified the gender-driven battle that home economics fought as it strove to coalesce into a recognizable, and respectable, discipline. "339" and "640" served as a kind of shorthand for the twin aspects of the subject that represented a newer, more expansive subject, on the one hand, and a more traditional, gender-bound subject, on the other. Regardless of the high standards for research established by such pioneers as Ellen Richards of MIT, Isabel Bevier of the University of Illinois, and Agnes Fay Morgan of the University of California at Berkeley, as long as university departments of home economics were run by women they faced nearly insurmountable obstacles in avoiding second-class status. ${ }^{31}$

The attitudes that colored the discipline's image reflected the culture as a whole. Quoting two male speakers to the American Home Economics Association in 1908-9, Sarah Stage describes a discourse that typically proscribed the definition of "home": they "[c]onsistently adopted a more literal definition that emphasized the home as a physical space presided over by a woman helpmeet yet firmly under the control of male authority. Conceiving of the home in these terms did not so much undercut woman's moral authority as circumscribe it. ${ }^{33}$ Similarly, Nancy Folbre notes that women's place in turn-of-the-century economics was similarly circumscribed by the authority of male economists who "considered women's unpaid labor in the home morally important but economically unproductive" until the advent of the home economics movement. ${ }^{34}$

The DDC can be read as an artifact of the culture that produced it. Chronicling the importance of the Amherst College curriculum, textbooks, and faculty to Dewey's 1870s undergraduate education, Wiegand writes, "Like the rest of his classmates Dewey looked upon the world reflected in this curriculum as objective and absolute," part of a "cultural milieu." In fact, Dewey even may have gotten the idea for using Sociology as a major heading under which to gather such DDC subclasses as Political Economy, Political Science, and Administration from a 
seminar taught by John W. Burgess, who believed that "private property was the logical conclusion of human development." "[T]he hierarchical arrangement of headings Dewey ultimately devised for the decimal scheme," concludes Wiegand, "had the effect of framing and cementing a worldview and knowledge structure taught on the tiny Amherst College campus between 1870 and 1875 into what became the world's most widely used library classification," a scheme that "has quietly-almost invisibly_occupied an influential position as one of the forces sustaining the discursive formations of a Eurocentric patriarchy." ${ }^{35}$

Even John Phillip Comaromi, a modern historian of the DDC, reveals a certain patriarchal bias in his analysis of the placement of domestic economy within the DDC. In his history of the DDC, he concludes that Domestic Economy's hierarchical placement in the first edition under 600 Useful Arts "was not determined by a classifier's arbitrary decision to give more importance to one division than another." Rather, it was placed "reasonably enough" after Agriculture, because food was a product of agriculture. Comaromi, however, admits that he cannot explain all the other subtopics of Domestic Economy, for instance, servants and furniture, that were not products of agriculture. Instead, he reasons, somewhat condescendingly, "Without straining too much, one can consider domestic economy a useful art that employs a great many little skills. However, should it be raised to the same level as medicine or engineering or any of the other skills with a heading in the Useful Arts?"16

This is not to disrespect Comaromi but, rather, to point out the assumptions that underlie classification systems as well as analyses of those systems. The result of trying "to impose a universal language of classification on information characterized by mainstream Western scholarship," writes Hope Olson, is that certain subjects and groups of people that do not fit easily under those rubrics inevitably are going to be marginalized. "We are left with the perceptions of how important a subject is in some absolute sense as the determinant of its pigeonholing, its spatial positioning," both in terms of the amount of space given over to a topic and its proximal relationships. ${ }^{37}$ In the case of home economics, quite a bit of "space" was given over in terms of additional subdivisions added to the 640 s in the seventh edition. Its "proximal relationship" to the 300 s, however, did not change at all. In fact, Olson notes that even today the treatment of household labor under 640.46 is skewed, with no room in the classification for those who perform unpaid labor in the home, the homemakers. ${ }^{38}$

At the tenth conference, in 1908, Ellen Richards looked back and recalled that at the beginning of the conferences "it was evident that a name and an organized body of knowledge were needed to gain recognition from the intelligent and especially from the academic class. ${ }^{39}$ This description of purpose best fits the "ideal" or "theoretical" classification described by Francis Miksa that "began with an ideal conception of all subjects and, on the basis of that beginning point. .. would develop subject structures which were logically consistent and which were perceived to be accurate by specialists." Dewey, on the other hand, was a "practical" man, a "businessman," as Miksa describes him, who believed in a classification that "would accommodate new knowledge though without the kind of intellectual squabbles that were associated with specialists, and regardless of such growth in knowledge."

Given such a paradigm, if the early home economists considered their effort to relocate the "relational" aspects of their discipline to 339 as a battle to be won, they were bound to lose. Disagreements over names and a flimsy bibliography hardly helped their cause. Furthermore, by the time of Richards's death in 1911, the ideology of the home economics movement was becoming more politically conservative, less reform minded, and more inner directed under the leadership of efficiency expert Christine Frederick. This turn seems to have vindicated Melvil 
Dewey's conservative tendencies regarding the DDC and left unquestioned any gender-driven aspects of the placement of home economics within the classification system.

In the fifteenth edition of the DDC, however, human ecology, the name now used by many university programs that encompass home economics programs, did find a place in 301.6. In the nineteenth edition marriage and family found a place in 306.8. These and other headings reflect the more interdisciplinary vocabulary used by the American Association of Family and Consumer Sciences, the successor to the American Home Economics Association, and perhaps foreseen by those who attended the Lake Placid conferences. The fact that the placement of home economics within the DDC was of such considerable moment, however briefly, to the founders of the discipline testifies to that classification system's importance as a scheme of knowledge by which those early home economists sought to define their subject and themselves.

\section{Notes}

The authors are grateful to Billie J. Collier, interim associate vice president for research and chief research officer, University of Tennessee, Knoxville, for asking the questions and to Connie Van Fleet, associate professor, School of Information Studies, University of Oklahoma, for bringing them to our attention. Without their actions and input along the way this paper never would have been written.

1. Sarah Stage, "Introduction: Home Economics, What's in a Name?" in Sarah Stage and Virginia B. Vincenti, eds., Rethinking Home Economics: Women and the History of a Profession (Ithaca, N.Y.: Cornell University Press, 1997), 4.

2. Lake Placid Conference on Home Economics, Proceedings of the Fourth Annual Conference: September 16-20, 1902 (Lake Placid, N.Y., 1902), 71-72 (hereafter cited as LPC Fourth).

3. Wayne Wiegand, Irrepressible Reformer: A Biography of Melvil Dewey (Chicago: American Library Association, 1996), 251-52.

4. Lake Placid Conference on Home Economics, Proceedings of the Sixth Annual Conference, September 19-24, 1904 (Lake Placid, N.Y., 1904), 63 (hereafter cited as LPC Sixth).

5. Wiegand, Irrepressible Reformer, 263.

6. Lake Placid Conference on Home Economics, Proceedings of the First Annual Conference, in Proceedings of the First, Second and Third Conferences: September 19-23, 1899; July 3-7, 1900; June 28-July 5, 1901 (Lake Placid, N.Y, 1901), 4 (hereafter cited as LPC First).

7. Lake Placid Conference on Home Economics, Proceedings of the Eighth Annual Conference, September 15-22, 1906 (Lake Placid, N.Y, 1906), 32 (hereafter cited as LPC Eighth).

8. Lake Placid Conference on Home Economics, Proceedings of the Tenth Annual Conference. By Special Invitation Held at Chautauqua, NY: 6-10 July 1908 (Lake Placid, N.Y, 1908), 156 (hereafter cited as LPC Tenth).

9. Annie Dewey and Melvil Dewey, "Mrs. Ellen H. Richards: Her Relation to the Lake Placid Conference on Home Economics," Journal of Home Economics 3, no. 4 (1911): 351.

10. Lake Placid Conference on Home Economics, Proceedings of the Second Annual Conference, in Proceedings of the First, Second and Third Conferences, 36 (hereafter cited as LPC Second).

11. For a wide-ranging overview of this period in the development of organized knowledge, see Alexandra Oleson and John Voss, eds., The Organization of Knowledge in Modern America, 18 60-1920 (Baltimore, Md.:Johns Hopkins University Press, 1979).

12. LPC First, 6.

13. LPC Second, 24.

14. Melvil Dewey, Decimal Classification and Relativ Index for Libraries Clippings, Notes, Etc., 6th ed. (Boston: Library Bureau, 1899), emphasis added.

15. "The Lake Placid Conference to Its Chairman, Mrs. Ellen H. Richards, Greeting," Journal of Home Economics 3, no. 4 (1911): 354. This testimonial was footnoted as having been presented at the Lake Placid conference of 1905 .

16. Robert Kendall Shaw, Bibliography of Domestic Economy in English: New York State Library Bulletin No. 52, January 1901, Bibliography 22 (Albany: University of the State of New York). 
17. LPC Sixth, 67.

18. LPC Eighth, 115.

19. Melvil Dewey, Decimal Classification and Relativ Index for Libraries Clippings, Notes, Etc., 7th ed. (Lake Placid, N.Y.: Forest Press, 1911). Like the sixth edition, this one was edited by May Seymour, with Walter S. Biscoe's assistance and under Melvil Dewey's supervision.

20. John P. Comaromi, "The Historical Development of the Dewey Decimal Classification System," in Kathryn Luther Henderson, ed., Major Classification Systems: The Dewey Centennial (Urbana-Champaign: Graduate School of Library Science, University of Illinois, 1976), 23.

21. Melvil Dewey, Decimal Classification and Relativ Index for Arranging Cataloging and Indexing Public and Private Libraries and for Pamflets, Clipps, Notes, Scrap Books, Index Rerums, Etc., 2nd ed., revised and greatly enlarged (Boston: Library Bureau, 1885), 46.

22. Melvil Dewey, "Decimal Classification Beginnings," Library Journal, 15 June 2000: 89. First published in the Library Journal, 15 February 1920: n.p.

23. Melvil Dewey and W. S. Biscoe, "Comments on Dieserud's Suggested Classification," Library Journal 22, (November 1898): 609-10.

24. Isabella M. Cooper, ed., A.L.A. Catalog 1926: An Annotated Basic List of 10,000Books (Chicago: American Library Association, 1926).

25. See Emma Seifrit Weigley, "It Might Have Been Euthenics: The Lake Placid Conferences and the Home Economics Movement," American Quarterly 26 (March 1974): 79-96, for an overview of this history.

26. Quoted in LPC Eighth, 120.

27. Stage, "Introduction," 7.

28. Lake Placid Conference on Home Economics, Proceedings of the Ninth Annual Conference, July 1-6, 1907 (Lake Placid, N.Y., 1907), 7, 8.

29. LPCFourth, 72.

30. Henry Johnson, The Other Side of Main Street: A History Teacher from Sauk Centre (New York: Columbia University Press, 1943), 45. For serious discussion of the struggles of education faculty within academia and particularly the gendered nature of education as a discipline, see John I. Goodlad, "Whither Schools of Education?" Journal of Teacher Education 50 (1999): 325-38; Jurgen Herbst, And Sadly Teach: Teacher Education and Professionalization in American Culture (Madison: University of Wisconsin Press, 1989); and Ellen Conliffe Lagemann, An Elusive Science: The Troubling History of Education Research (Chicago: University of Chicago Press, 2000).

31. LPC Tenth, 155.

32. See Maresi Nerad, The Academic Kitchen: A Social History of Gender Stratification at the University of California, Berkeley (Albany: State University of New York Press, 1999) for a fascinating account of Agnes Fay Morgan's career.

33. Sarah Stage, "Ellen Richards and the Social Significance of the Home Economics Movement," in Stage and Vincenti, eds., Rethinking Home Economics, 30.

34. Nancy Folbre, "The 'Sphere of Women' in Early-Twentieth-Century Economics," in Helene Silverberg, ed., Gender and American Social Science: The Formative Years (Princeton, NJ.: Princeton University Press, 1998), 35 .

35. Wayne A. Wiegand, "The 'Amherst Method': The Origins of the Dewey Decimal Classification Scheme," Libraries \& Culture 33 (Spring 1998): 183-84, 186-87, 188, 190.

36. John Phillip Comaromi, The Eighteen Editions of the Dewey Decimal Classification (Albany, N.Y.: Forest Press Division, Lake Placid Education Foundation, 1976), 69, 70, 72-73.

37. Hope A. Olson, "Dewey Thinks Therefore He Is: The Epistemic Stance of Dewey and the DDC," Advances in Knowledge Organization 5 (1996): 306.

38. Hope A. Olson, "Mapping beyond Dewey's Boundaries: Constructing Classificatory Space for Marginalized Knowledge Domains," Library Trends 47 (Fall 1998): 243-45.

39. LPC Tenth, 20-21.

40. Francis L. Miksa, The DDC, the Universe of Knowledge, and the Post-Modern Library (Albany, N.Y.: Forest Press, 1998), 11-12. 